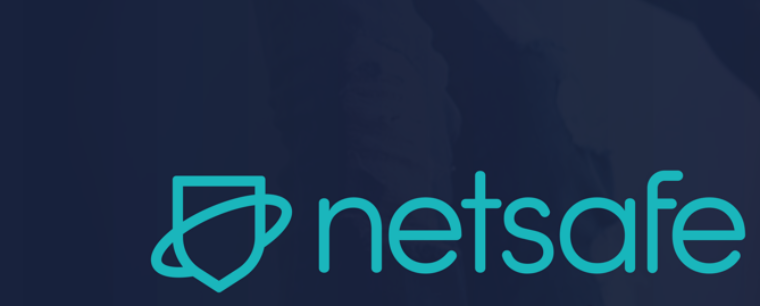

\title{
netsafe.org.nz
}
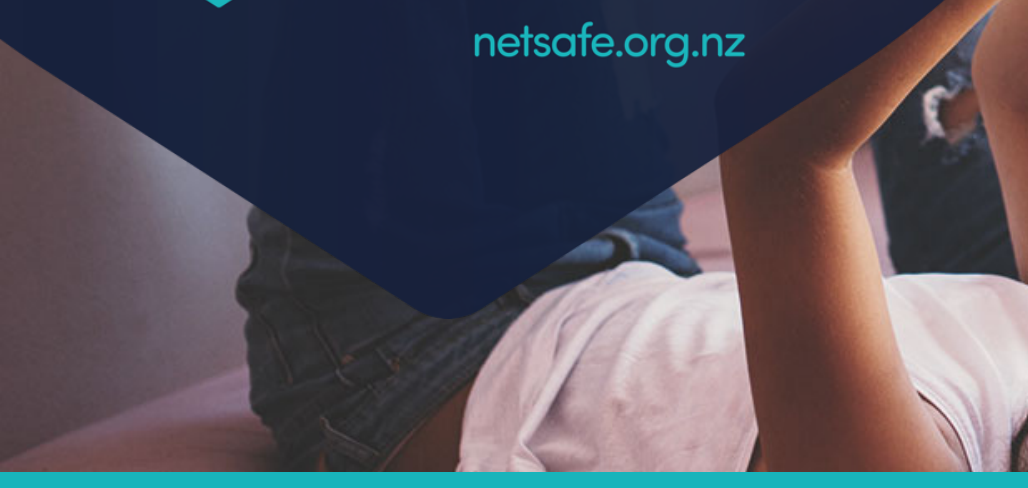

\section{New Zealand Teens and digital harm: Seeking and accessing support}

\author{
PREPARED BY DR. EDGAR PACHECO AND \\ NEIL MELHUISH
}

\section{What is this about?}

This factsheet is part of a larger quantitative research project led by Netsafe in partnership with the Ministry for Women exploring New Zealand teens' experiences of digital risk and harm. It presents findings about the support sought by 14 to 17-year-olds who experienced unwanted digital communications ${ }^{1}$ in the prior year. More specifically, it reports on who they turned to for support, the reasons for their choice, and the perceived usefulness of any help they received.

The findings highlight the important role that family (particularly parents) and close friends play in the actions teenagers take to cope with online incidents ${ }^{2}$.

\section{Summary of findings}

- Two thirds of teens who experienced one or more unwanted digital communications in the prior year sought someone's support.

- About half of those who sought support approached their parent or caregiver.

Nearly a third preferred the help of a close friend.

- In contrast, just over a third (34\%) did not contact anyone for help.

- Girls were more likely to seek support from a close friend compared to boys.

- While it was more common for younger teenagers to seek support from their parents or caregivers, older teens preferred to contact a close friend.

- Nearly 8 in 10 participants commented that 'trust' was behind their decision to ask for the support of a parent/caregiver or a close friend.

- Also, a large majority (over 8 in 10) considered that the support received was helpful.

Defined as an online experience(s) mediated/facilitated by an unsolicited electronic communication(s) that might or might not cause distress and/or harm to the person who deals with it (e.g., receiving spam, seeing inappropriate content, or being threatened online). 
This factsheet is for parents and educators who are seeking to better understand teens' experiences of online risks and challenges, and to provide appropriate support to teens in their care. For service providers and government agencies these evidence-based insights can inform policy development and help to improve prevention and service delivery to young New Zealanders, so they can take advantage of new technologies while safely navigating the digital environment.

\section{What we know so far}

Recent research conducted by Netsafe and the Ministry for Women has explored the relationship between New Zealand teens and their online environment, and its implications for digital harm. Evidence shows that technologies, such as social media and mobile devices, play a key part in the everyday life of teenagers. However, a significant number of teens have experienced unwanted digital communications, and these experiences are more likely to negatively affect girls than boys (see Ministry for Women, 2017; Netsafe, 2018a, 2018b).

On the topic of teens' access to support, our previous research has provided some interesting insights. Findings based on focus group data reveal that teens perceive little in the way of useful formal support being in place for them; barriers to seeking help include personal concerns about their behaviours being exposed to others (Ministry for Women, 2017). In addition, insights based on representative data show that when asked about what support teens would seek if they received an unwanted digital communication in the future, teens said they would first turn to parents and close friends for help and, to a lesser extent, the police or a teacher (Netsafe, 2018b).

This factsheet complements this evidence by reporting on teens' actual help-seeking behaviour, and their views on how effective this was in managing unwanted digital communications.

\section{What we did}

We conducted a nationally representative survey with a sample of 1001 teenagers aged from 14 to 17 in the second semester of 2017. This factsheet only reports the responses of those participants who said they experienced an unwanted digital communication $(n=689)$ in the prior year.

As previously mentioned, the focus is on teens' seeking and accessing support. By this we mean teens reaching out to people and organisations for help in resolving an online incident. Personal actions teens took to manage online incidents (e.g. blocking or unfriending someone) have already been reported in a previous study (see Netsafe, 2018b).

Netsafe, with support from the Ministry for Women, planned and designed the research instrument. Data collection and initial analysis was carried out by Colmar Brunton. The margin of error of this study is $+/-3.7 \%$ on the specific sample (teens who have experienced unwanted digital communications).

\section{What we found}

\section{SEEKING AND ACCESSING SUPPORT}

Of those participants who experienced unwanted digital communications, two thirds sought support to deal with a range of online incidents.

Parents or caregivers (46\%) were the most common source of support followed by a close friend (32\%). Less significant were a close relative, such as sister or brother (7\%), and a teacher (4\%). Interestingly, just over a third of respondents said they did not seek support from anyone in the list of options provided to them (34\%) - see Figure 1.

Girls (39\%) were significantly more likely to seek support from a close friend than boys (24\%). In contrast, boys (37\%) were more likely than girls (31\%) not to contact anyone for support. 


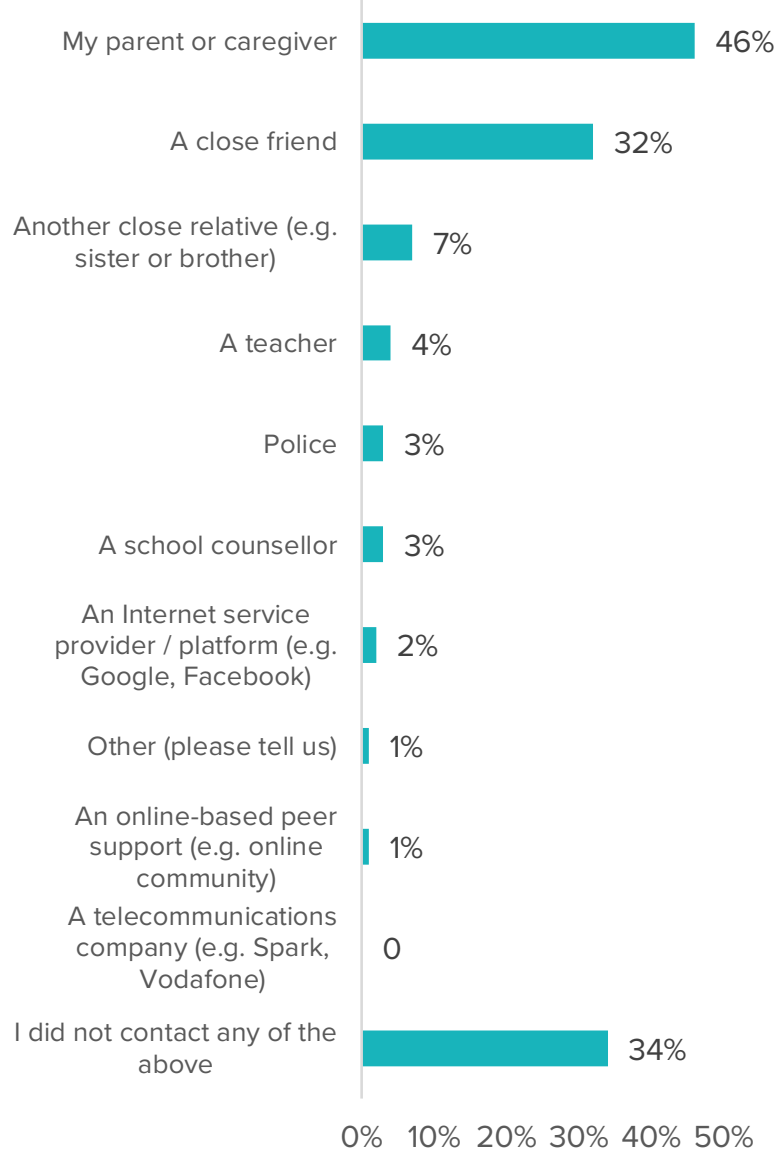

Figure 1. Types of support accessed by teens

Base: Respondents who had experienced at least one incident of unwanted digital communication in the last year (689)

For younger teenagers (those aged 14 and 15 years old) it was more common to seek support from their parents or caregivers while older teens ( 16 and 17 years old) preferred a close friend: specifically, 57\% for teens aged 14 years and $47 \%$ for those aged 15 years.

Meanwhile, for 17 -year-olds (35\%) contacting a close friend for help was more common.

The percentage of Māori (55\%) and Pacific teens (48\%) who reported having looked for support from their parent or caregiver was higher than in other ethnic groups.

For teens with disabilities who experienced an unwanted digital communication, seeking help from a parent/caregiver (49\%), a close friend (35\%), and a teacher (6\%) was more common than for non-disabled teens (45\%, 31\%, and 3\%, respectively).

\section{MAIN SOURCE OF SUPPORT}

A follow-up question asked those participants who sought the support from more than one of the listed options in the previous question $(n=441)$ to specify who they relied as their main source of support.

Among these participants, over half (58\%) said a parent or caregiver was their main source of help while $31 \%$ indicated a close friend was considered the most important source to manage an unwanted digital communication see Figure 2.

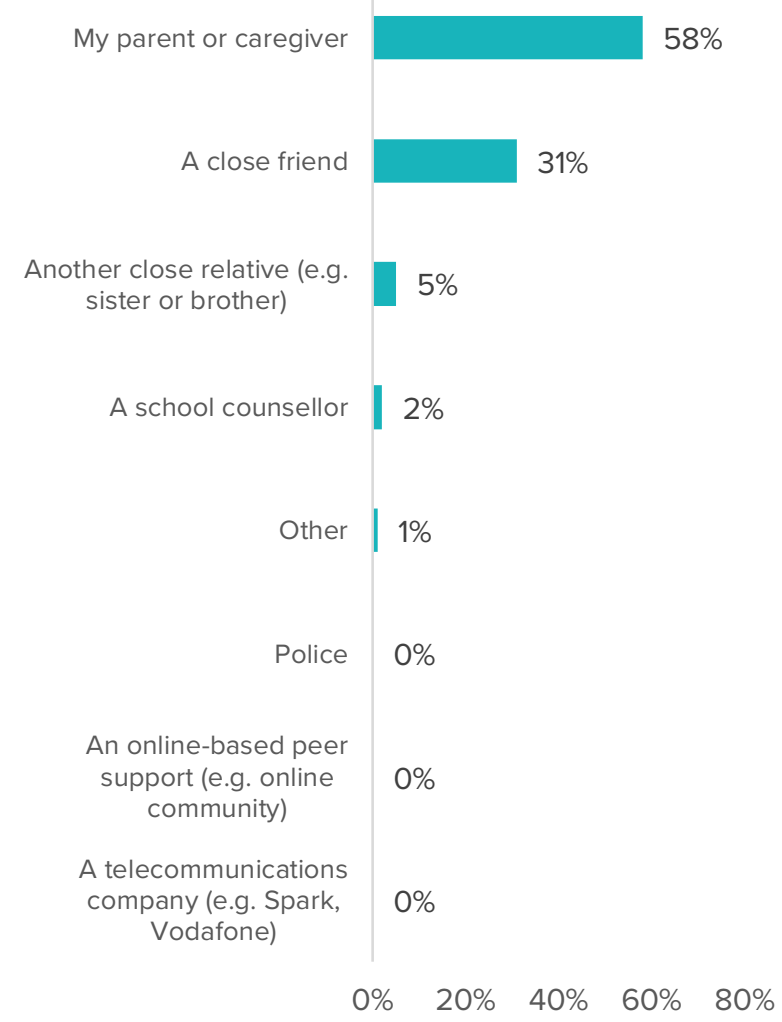

Figure 2. The main types of support accessed by teens

Base: Respondents who had experienced at least one incident of unwanted digital communication in the last year (441)

There was no significant statistical difference regarding girls' and boys' preference for a parent/caregiver as the main source of support. However, help from a close friend was higher among girls (35\%) than boys (28\%).

In terms of age, it was more common among younger teens to mention a parent/caregiver 
as the main source of support compared to older teens. For instance, the percentage of 14 -year-olds (64\%) was higher than that of 17year-olds (50\%). Also, 17 -year-olds (40\%) were almost twice as likely to ask a close friend for help compared to 14 -year-olds (22\%).

\section{REASONS FOR CHOOSING SUPPORT}

The survey included an open-ended question asking participants to explain in their own words the reasons for approaching their chosen source of support. The purpose of asking this question was to identify key themes or categories based on their perceptions. A total of 441 participants responded to the question.

Trust is a key reason for seeking help. Nearly 8 in 10 participants commented that trust was behind their decision to ask for the support of a family member (mostly parents and in some cases siblings) and/or a close friend.

For those who sought help from their parents, this trust was based on openness, listening, and the supportive relationship they said they have with them. For example, several participants indicated having good communication with their parents, who often talk and advise them about being safe. Teenagers said trust was mainly built and maintained because their parents are "easy to talk to", do not "make a big deal" about incidents, and are there to "help you unconditionally." In addition to advice and emotional support, parents also helped participants in dealing with instances such as hacking, talking with the school, and/or confronting a stranger online or whoever sent an unwanted digital communication.

Trust was also related to participants' perceptions that their parents have the experience and knowledge to manage risks and challenges in general. Several participants commented that their parents "know how to guide" or "have a good answer" regarding coping with online incidents. Some teens also pointed out that having previously received support and advice about personal and school-related issues motivated them to look for the support of their parents. Interestingly, several teens, particularly girls, stressed the role of their mums in coping with online incidents. These participants indicated that their mums not only were "good at sorting stuff" and "very supportive", but also understood "stuff about teens".

In a few cases, instead of trust, it was parents' control and supervision that led teens to ask for their support. For example, one participant commented on being "raised in discipline family [sic]". Another indicated they had "to be upfront" because their parents regularly "check my devices". However, parents' monitoring also created discomfort as one teen described it: "My parents access my accounts until I am 18 [sic]. I don't like these rules and have discussed it with them".

As previously described, close friends were the second most important source of support for participants who experienced unwanted digital communications. Again, trust was an important reason for asking for their support. Participants commented, for instance, that a close friend "would not overreact" about an online incident, "would listen without getting in trouble", "would be more reliable", and that they are of a "similar age....and help you to understand what is going on."

Another theme that emerged from the analysis was familiarity of their source of support with either the sender or the specific online incident. In this respect, just over 1 in 10 said they sought someone's help, especially a close friend, because they knew the sender of the unwanted digital communication. These participants commented, for example, that their friends helped them to deal with the sender who was an acquaintance or part of their social network. Some participants indicated, for example, that their close friends "knew the person that sent the inappropriate pic [sic]", that "it turned out to be their friends", that they also knew "what that person [sender] 
is like" and that they asked for their help because "it was about a girl at school". One participant said they turned to their best friend so they "could collectively confront them the next day." Others indicated they relied on their close friends because they were contacted by or had confronted the same person in the past. As one participant put it: "My close friend got contacted by the same person so of course the close friend was who I told first."

In a few cases participants did not actively seek support but received it anyway due to proximity. These participants, for instance, indicated that their parents or a close friend were "right beside me" when the online incident happened.

Some participants did not answer the question directly but preferred to give reasons why they did not ask their parents for support. These respondents indicated that they wanted to avoid embarrassment or worrying them about the online incident.

\section{PERCEIVED HELPFULNESS OF SUPPORT}

Participants were also asked about the perceived helpfulness of the support they received. The large majority (over 8 in 10) had a positive impression and indicated support received was helpful/very helpful - this was particularly the case for those who asked parents/caregivers for help. Only $2 \%$ say the support they received was 'not helpful' - see Figure 3.

In terms of gender, the overall positive perception of the usefulness of the support received was slightly higher for girls (86\%) than boys (81\%). No significant statistical differences were found in terms of age groups. For some ethnic groups the perceived usefulness of support was higher compared to others. While Māori (91\%) and Asian teenagers (87\%) said their source of support was helpful/very helpful, NZ European/Pākehā $(82 \%)$ and Pacific teens (82\%) considered it less so.

\section{In their own words}

- I feel I can tell my parents anything and normally they have a good answer.

- Male, 16, NZ European/Pākehā

- Because I trust them [parents] and they contacted the school. They are calm and also they have helped with previous issues. - Female, 14, NZ European/Pākehā

- My mum gets results and doesn't judge. - Male, 16, NZ European/Pākehā

- I didn't want my parents to worry and I feel I'm old enough to deal with it.

- Female, 17, NZ European/Pākehā

- I am encouraged to tell my parents everything, no matter whether I am in the right or wrong. I will never be told off, just thanked for telling them and we work our way through things.

- Female, 15, NZ European/Pākehā

- [My friend] Had a similar experience and made problem go away.

- Male, 16, Māori

- I didn't want to deal with it myself, so I turned to the closest friend I had.

- Male, 17, NZ European/Pākehā

- She [a close friend] knew the person that sent the inappropriate pic.

- Female, 17, NZ European/Pākehā

- Teenagers feel embarrassed to go to their parents ... a close friend might help you understand what is going on because he/she/it might have gone through something similar.

\section{- Female, 15, NZ European/Pākehā}

- 'Cause my parents don't understand and my friend would get it, and I would not need to explain the whole thing to my friend but I would to my parents.

- Female, 16, NZ European/Pākehā

- Too embarrassing to go to an adult. Easier to go to a friend, they understand.

- Female, 16, NZ European 
On the other hand, while a large proportion of teens with disabilities (79\%) perceived that their source of support was helpful/very helpful, this percentage was slightly lower compared with the views of non-disabled teens (84\%).

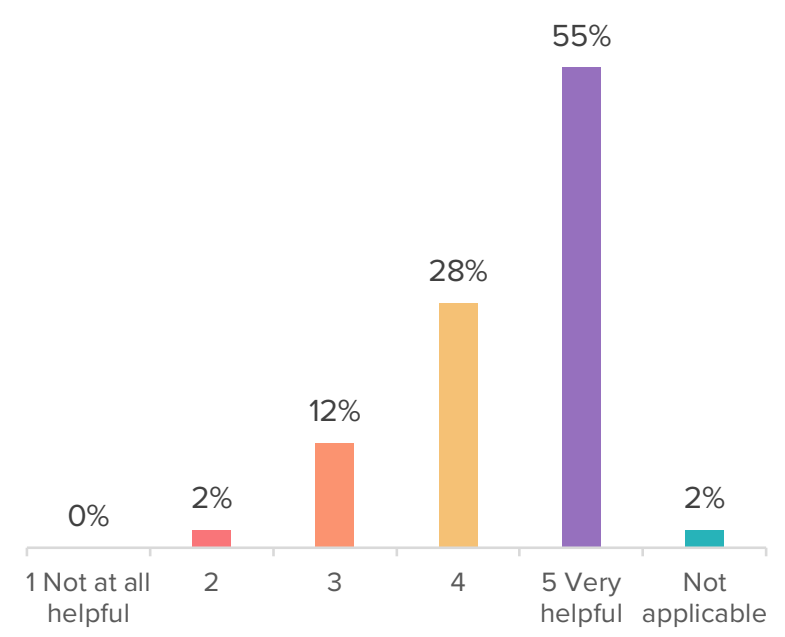

Figure 3. Perceived helpfulness of support received

Base: Respondents who had experienced receiving at least one unwanted digital communication in the last year (689)

\section{Concluding remarks}

This factsheet has presented findings about the support sought and accessed by teens, aged 14-17 years old, to manage unwanted digital communication, the reason for approaching their source of support, and the perceived usefulness of the help received.

The findings show that parents, followed by close friends, are the first line of support in dealing with unwanted digital communications. These insights are in line with international research that has highlighted how important and beneficial these types of social connections are for teens in the context of online risks and challenges (see Dowling \& Carey, 2013; Duerager \& Livingstone, 2012; Fridh, Lindström, \& Rosvall, 2015).

As teens mostly connect online at home, parents not only have the responsibility but are also best positioned to guide their children's online experiences (Mascheroni, Murru, Aristodemou, \& Laouris, 2013).
Further, our study suggests that positive social mediation, based on the emotional support and practical help provided both by parents and close friends, can help teens to manage digital harm and distress. As the findings show, parents' and friends' support is not only highly regarded by teens but is also perceived to be effective. Therefore, policies and programmes aimed at preventing digitally mediated harm should consider and encourage this form of support.

Our insights are also consistent with findings from our prior qualitative research (see Ministry for Women, 2017) in which older teens (16 and 17 years old) indicated their preference for the support of close friends. Furthermore, by including the experiences of younger teens (15 and 16 years old), this study reveals that the role of parents in regard to these teens' experiences of digital harm is more prominent.

In addition, another study (see Netsafe, 2018b) indicated that teenagers would primarily seek the help of parents and then close friends if they experienced unwanted digital communications in the future. As described in this factsheet, the findings confirm this helpseeking behaviour among New Zealand teens who had these experiences in real life.

Another key finding is the importance of trust in the help-seeking behaviour of New Zealand teens. As participants' comments indicate, trust is largely the reason for seeking the support of parents and friends. This point has implications for parents of teens who look for help. According to teens, parents having open communication with their children, listening to them, and not being judgemental about experiences of risk and online behaviour are useful attitudes and foster an environment of trust. This point is particularly relevant for younger teens who relied more on the support of their parents than their older peers. Thus, it is necessary for parents to invest in the quality of the relationship with their children, so online incidents are not only positively responded to but also prevented. 
Our insights also have implications for schools and educators. Considering that most parents would like online safety information to be provided by their kids' school (Staksrud \& Ólafsson, 2013), there is a role that schools still play in supporting parents' efforts to prevent or manage experiences of digital harm. Permanent and open dialogue with parents will provide schools with a better idea of the type of information and resources parents need, which can help them to build closer relationships with their children.

The understanding of teens' help-seeking behaviour in the context of digital harm requires further exploration. This factsheet presents representative, but high level, findings based on key demographics (age, gender, ethnicity and disability). However, evidence about specific groups of teenagers such as those at greater risk (e.g. exposure to family violence) is non-existent to the best of our knowledge. Research and policy will need to address the situation of vulnerable teens (for instance, whether they seek support, and how effective it is) as they are more likely to be affected by negative online experiences (Odgers, 2018).

\section{What's next?}

Evidence from this factsheet and our previous research is contributing to Netsafe's development of new online safety resources and tools for parents and caregivers, family, whānau, and schools and kura.

A recent example is the new version of the Netsafe Kit. This resource provides comprehensive information for educators on a range of topics including strategic approaches to planning and responding to online incidents. A key aspect is the role of family and whanau in the digital life of their students and the wider school community. The Kit will be available from July 2018 and can be accessed at https://www.netsafe.org.nz/the-kit/

\section{References}

Dowling, M. J., \& Carey, T. A. (2013). Victims of bullying: Whom they seek help from and why: An Australian sample. Psychology in the Schools, 50(8), 798-809. https://doi.org/10.1002/pits.21709

Duerager, A., \& Livingstone, S. (2012). How can parents support children's internet safety? Retrieved from http://eprints.Ise.ac.uk/42872/

Fridh, M., Lindström, M., \& Rosvall, M. (2015). Subjective health complaints in adolescent victims of cyber harassment: Moderation through support from parents/friends - a Swedish population-based study. BMC Public Health, 15(1), 949. https://doi.org/10.1186/s12889-015-2239-7

Mascheroni, G., Murru, M. F., Aristodemou, E., \& Laouris, Y. (2013). Parents. Mediation, selfregulation and co-regulation. In B. O'Neill, E. Staksrud, \& S. McLaughlin (Eds.), Towards a Better Internet for Children?: Policy Pillars, Players and Paradoxes (pp. 211-225). Gotenborg: Nordicom.

Ministry for Women. (2017). Insights into digital harm: The online lives of New Zealand girls and boys. Wellington, New Zealand. Retrieved from http://women.govt.nz/documents/insights-digitalharm-online-lives-new-zealand-girls-and-boys

Netsafe. (2018a). New Zealand teens' digital profile: $A$ Factsheet. Retrieved from https://www.netsafe.org.nz/wpcontent/uploads/2017/12/SEXTING-NZ-Report-Dec7-2017v2-2.pdf

Netsafe. (2018b). New Zealand teens and digital harm: Statistical insights into experiences, impact and response. Retrieved from https://www.netsafe.org.nz/NZ-teens-and-digitalharm_statistical-insights_2018.pdf

Odgers, C. (2018). Smartphones are bad for some teens, not all. Nature, 554(7693), 432-434. https://doi.org/10.1038/d41586-018-02109-8

Staksrud, E., \& Ólafsson, K. (2013). Awareness. Strategies, mobilisation and effectiveness. In B. O’Neilll, E. Staksrud, \& S. McLaughlin (Eds.), Towards a Better Internet for Children?: Policy Pillars, Players and Paradoxes (Nordicom, pp. 5776). Goteborg. 
NEW ZEALAND TEENS AND DIGITAL HARM: SEEKING AND ACCESSING SUPPORT

Wellington, New Zealand, June 2018

www.netsafe.org.nz

research@netsafe.org.nz

Recommended citation: Netsafe. (2018). New Zealand teens and digital harm: Seeking and accessing support. Retrieved from: https://www.netsafe.org.nz/youth-accessing-support-factsheet-2018

ISBN: 978-0-473-44503-4 